\title{
Prevalence and correlates of severe hypoglycaemia among patients with youth onset diabetes in India
}

\author{
Nikhil Tandon' ${ }^{1}$, A Amutha ${ }^{2}$, K Singh ${ }^{3}$, U Shankar ${ }^{1}$, T Kaur ${ }^{4}$, RS Dhaliwal ${ }^{4}$, A K Das ${ }^{5}$, C S Yajnik ${ }^{6}$, V Mohan ${ }^{2}$, P A Praveen ${ }^{1}$ \\ ${ }^{1}$ All India Institute of Medical Sciences, New Delhi, India, ${ }^{2}$ Madras Diabetes Research Foundation, Chennai, India, ${ }^{3}$ Public Health Foundation of \\ India, New Delhi, India, ${ }^{4}$ Indian Council of Medical Research, New Delhi, India, ${ }^{5}$ Pondicherry Institute of Medical Sciences, Puducherry, India, \\ ${ }^{6}$ King Edward Memorial Hospital and Research Centre, Pune, India
}

\section{Background}

Hypoglycaemia is the most common acute complication in type 1 diabetes. It may also occur in type 2 diabetes when treatment includes insulin or insulin secretagogues. The threat of incidence of hypoglycaemia is the limiting factor for intensive glycaemic control in diabetes management.

\section{Objectives}

* To estimate the burden of hypoglycaemia in patients with youth onset type 1 and type 2 diabetes

* To identify the risk factors of severe hypoglycaemia in youth onset diabetes

\section{Methods}

* A cross sectional study was conducted among patients with youth onset type 1 and type 2 diabetes registered at the All India Institute of Medical Sciences (AIIMS), New Delhi and Madras Diabetes Research Foundation (MDRF), Chennai centres of the registry of people with youth onset diabetes in India (YDR).

* The patients who attended the above clinics between $1^{\text {st }}$ July 2013 and $31^{\text {st }}$ July 2015 were invited to participate in the study.

* History of hypoglycaemia was captured using a structured questionnaire and the categories were defined as per the American Diabetes Association's hypoglycaemia working group recommendations.

- Probable symptomatic hypoglycaemia: History of typical symptoms of hypoglycaemia (palpitations, tremor, hunger, or sweating) in the past one year

- Severe hypoglycaemia: History of hypoglycaemia episodes in which patients needed assistance from other persons during the preceding year

* Self-care activities [physical activity (30 minutes of moderate to vigorous activity per day), adherence to diet plan and selfmonitoring of blood glucose (SMBG)] were assessed using the Summary of Diabetes Self-Care Activities (SDSCA) questionnaire, which is a brief questionnaire that asks how many days per week an activity was performed.

\section{Results}

* The prevalence of probable symptomatic hypoglycaemia in type 1 and type 2 diabetes patients, who attended two tertiary care hospitals in India, was $50.8 \%$ and $45.5 \%$ respectively.

* The prevalence of severe hypoglycaemia was significantly higher among type 1 diabetes patients $(13.4 \%)$ compared to type 2 diabetes (3.4\%) (Figure-1)
* The factors associated with severe hypoglycaemia in type 1 diabetes patients were: irregular self-monitoring of blood glucose and non-adherence to the prescribed weekly diet plan (Table-1).

* The study was not adequately powered to analyse the risk factors of hypoglycaemia in patients with youth onset type 2 diabetes.

\section{Figure-1: Prevalence of hypoglycaemia in type 1 and type 2 diabetes}

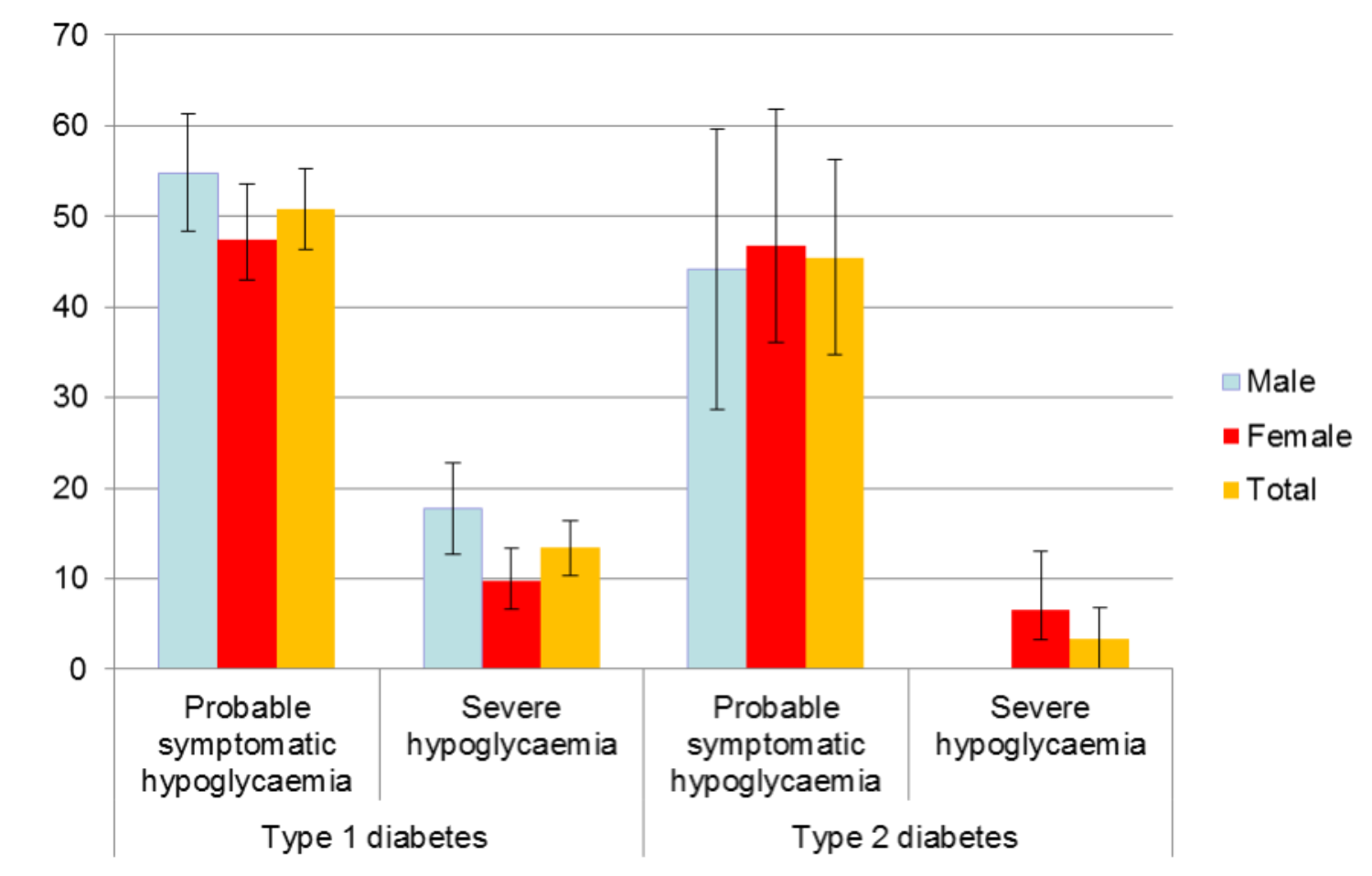

Table-1: Risk factors of hypoglycaemia in type 1 diabetes

\begin{tabular}{|c|c|c|}
\hline Factor & $\begin{array}{l}\text { Adjusted odds } \\
\text { ratio }(95 \% \mathrm{Cl})\end{array}$ & P value \\
\hline Current age (1 year) & $1.0(0.9,1.02)$ & \multirow{2}{*}{0.8} \\
\hline Gender & & \\
\hline Female & Ref & \multirow{2}{*}{0.1} \\
\hline Male & $1.6(0.9,2.8)$ & \\
\hline $\begin{array}{l}\text { Adherence to diet plan } \\
\text { (seven days per week) }\end{array}$ & & \\
\hline Yes & Ref & \multirow{2}{*}{0.003} \\
\hline No & $2.5(1.4,4.0)$ & \\
\hline $\begin{array}{l}\text { Regular self-monitoring of } \\
\text { blood glucose }\end{array}$ & & \\
\hline Yes & Ref & \multirow{2}{*}{$<0.001$} \\
\hline No & $4.5(2.1,9.5)$ & \\
\hline
\end{tabular}

Conclusions

* There is high burden of symptomatic hypoglycaemia among patients with youth onset type 1 and type 2 diabetes from India.

* This study highlights the importance of educating patients with youth onset diabetes and their families in terms of hypoglycaemia
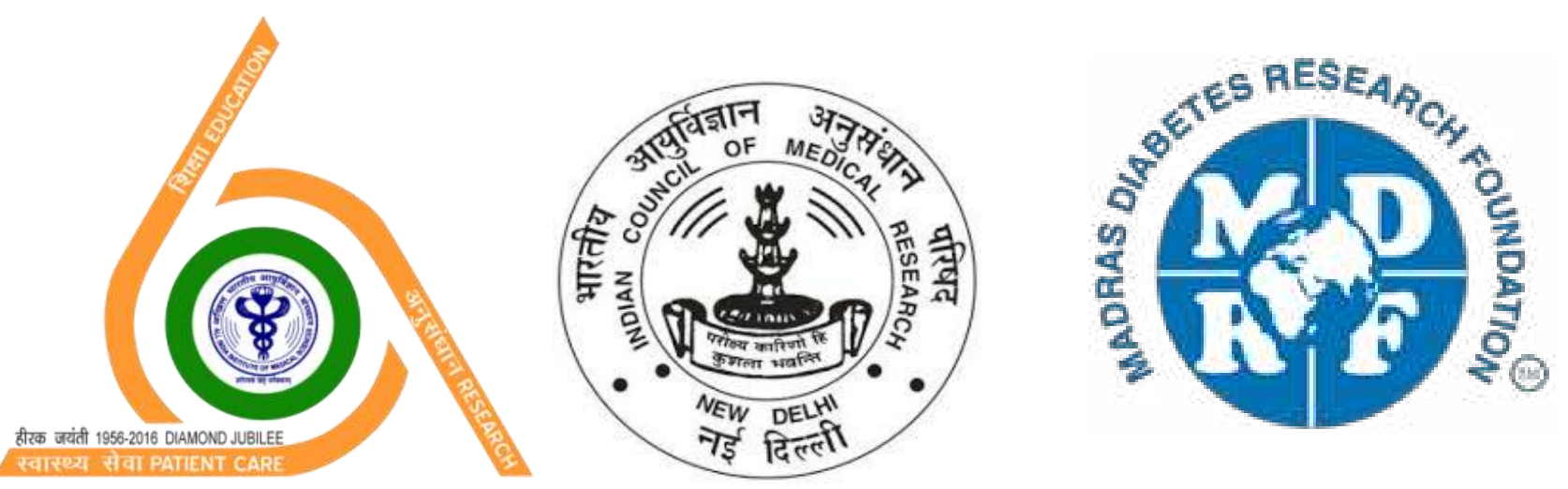